\title{
APG-1252-12A induces mitochondria-dependent apoptosis through inhibiting the antiapoptotic proteins Bcl-2/Bcl-xl in HL-60 cells
}

\author{
JING WANG $^{1 *}$, DAJUN YANG ${ }^{2,3 *}$, QIUYUN LUO ${ }^{2}$, MIAOZHEN QIU ${ }^{2}$, LIN ZHANG $^{2}$, \\ BAOXIA LI ${ }^{2}$, HAIBO CHEN ${ }^{2,4}$, HANJIE YI $^{2}$, XIANGLEI YAN ${ }^{2}$, SHUXIA LI $^{1}$ and JIAN SUN ${ }^{2}$ \\ ${ }^{1}$ Department of Pharmacy, The First Affiliated Hospital, Sun Yat-sen University, Guangzhou, Guangdong 510080; \\ ${ }^{2}$ State Key Laboratory of Oncology in South China, Collaborative Innovation Center For Cancer Medicine, \\ Sun Yat-sen University Cancer Center, Guangzhou, Guangdong 510060; ${ }^{3}$ Ascentage Pharma Group Inc., \\ Taizhou, Jiangsu 225309; ${ }^{4}$ Sun Yat-sen Memorial Hospital, Sun Yat-sen University, \\ Guangzhou, Guangdong 510120, P.R. China
}

Received February 20, 2017; Accepted May 22, 2017

DOI: $10.3892 /$ ijo.2017.4028

\begin{abstract}
Acute myeloid leukemia (AML) is the most common acute leukemia in adults. Despite improved remission rates, current treatment regimens for AML are often associated with a very poor prognosis and adverse effects, necessitating more effective and safer agents. B-cell leukemia/lymphoma 2 (Bcl-2) family proteins regulate apoptotic pathway that can be targeted with small molecule inhibitors. APG-1252-12A is a Bcl-2 homology ( $\mathrm{BH})-3$ mimetic that specifically binds to Bcl-2 and Bcl-xl, which has shown efficacy in some Bcl-2 dependent hematological cancers. In this study, we investigated whether APG-1252-12A inhibits the growth of five leukemia cell lines in a concentration- or time-dependent manner by MTS assay. Following treatment of AML cell line HL-60 with this compound, cell apoptosis was detected using flow cytometry and nuclear condensation was observed after Hoechst 33258 dye. Immunoblotting for cytochrome c, cleaved caspase-3 and PARP-1 cleavage was used to demonstrate the mechanism of inducing mitochondria-dependent apoptosis by APG-1252-12A. Our findings showed that this new compound inhibited cell proliferation in five leukemia cell lines and induced apoptotic death. There was a link between the level of Bcl-2 protein and $\mathrm{IC}_{50}$. APG-1252-12A targeted mitochondria
\end{abstract}

Correspondence to: Professor Shuxia Li, Department of Pharmacy, The First Affiliated Hospital, Sun Yat-sen University, 58 2nd Zhongshan Road, Guangzhou, Guangdong 510080, P.R. China E-mail: 13728043322@139.com

Professor Jian Sun, Department of Clinical Research, Sun Yat-sen University Cancer Center, 651 Dongfeng Road East, Guangzhou, Guangdong 510060, P.R. China

E-mail: sunjian@sysucc.org.cn

*Contributed equally

Key words: acute myeloid leukemia, APG-1252-12A, Bcl-2/Bcl-xl inhibitor, BH3 mimetics, apoptosis and induced caspase-dependent apoptosis by inducing the HL-60 cell cytochrome $c$ released, PARP cleavage and caspase activation. These data suggested that APG-1252-12A is a candidate drug for the in vivo analysis and clinical evaluation in AML.

\section{Introduction}

Acute myeloid leukemia (AML) is a heterogenous hematological malignancy involving the clonal expansion of myeloid blasts in the bone marrow and peripheral blood with possible spread to liver and spleen. An estimated 19,950 people were newly diagnosed in 2016, 10,430 of whom will die from their disease (1). The 5-year survival rate for adult AML patients is only $26.6 \%$ based on 2006-2012 data, with a median age of 67 years at diagnosis (1). Overexpression of anti-apoptotic Bcl-2 proteins such as Bcl-2, Bcl-xl, and Mcl-1 occurs frequently in AML (2), which is widely associated with tumor initiation, progression, and drug resistance. Most AML patients become resistant to chemotherapy at some point in their course and succumb to their disease. Therefore, there is an urgent need to prevent chemoresistance or enhance chemosensitivity in a selective fashion to lead to a higher cure rate and a lower toxic burden.

Resisting cell death is a hallmark of cancer cells that contributes to tumour progression and to chemoresistance (3). Over the past three decades, over 16 members of the Bcl-2 family protein were identified and characterized (4). There are proapoptosis BH3-only proteins (such as Bim and Bad), proapoptosis multi-BH-domain proteins (such as Bak and Bax) and anti-apoptosis proteins (including Bcl-2, Bcl-xl, Mcl-1, Bfl1 and Bclw). The discovery of Bcl-2 started with a t(14;18) chromosomal translocations in human follicular lymphoma $(5,6)$. This protein has since been shown to have a dominant role in the survival of multiple lymphoid malignancies $(7,8)$. The pro-survival Bcl-xl protein, which was encoded by Bclx gene, was associated with drug resistance and disease progression of hematological malignancies (9). The dependence of AML 
cells on the anti-apoptotic Bcl-2 protein can be exploited for therapeutic effect using $\mathrm{BH} 3$ mimetics (10), a class of small molecules that mimic the inhibitory features of BH3-only proteins (11). Cancer cells have greater susceptibility to $\mathrm{BH} 3$ mimetic drugs than normal cells, partly because they often have higher levels of anti-apoptosis proteins and release more previously sequestered $\mathrm{BH} 3$-only proteins to activate Bax and Bak $(12,13)$.

ABT-737 (14) and ABT-263 (15), both developed by Abbvie Laboratories, displace pro-apoptotic proteins from Bcl-2 and Bcl-xl and have synergistic toxicity with conventional chemotherapeutics and radiation. They require Bax for cell killing and causing MOMP in Bcl-2 dependent cancer cells $(16,17)$, thus confirming an on-target effect. However, on-target thrombocytopenia caused by Bcl-xl inhibition limits the application of ABT-263. For the treatment of cancers that depend on Bcl-2, Bcl-2 selective inhibitor ABT-199 was created. ABT-199 does not reduce platelet lifespan and is better tolerated than ABT-263 (18). These mimetics have shown promising efficacy in various preclinical models and now in advanced clinical trials for chronic lymphocytic leukemia(CLL) and other malignancies (19-22).

Previously, our laboratory reported that small molecule Bcl-2 inhibitors ApoG2 and BM-1197 have potent antitumor effect on coloretal cancer cells $(23,24)$. APG-1252, a new BH3 mimetic that binds to Bcl-2 and Bcl-xl with sub-nanomolar affinities $\left(\mathrm{K}_{\mathrm{i}}<1 \mathrm{nM}\right)(25)$, was demonstrated with better in vivo antitumor activity than ABT-263 (26). APG-1252 achieved complete and long-term tumor regression in both $\mathrm{H} 146$ and H1963 SCLC xenograft models and avoid the commonly seen on-target toxicity when Bcl-xl is inhibited. APG-1252 converts into a more active metabolite APG-1252-12A (APG-1252-M1) in vivo. APG-1252-12A also binds with high affinity to Bcl-2 and Bcl-xl $\left(\mathrm{K}_{\mathrm{i}}<1 \mathrm{nM}\right)$ and is over ten times more active than APG-1252 (25). Regardless, the anti-tumor effect and underlying mechanism of APG-1252-12A have not yet been evaluated in leukemia. Herein, we report our detailed investigation of APG-1252-12A in HL-60 cells. These data showed that APG-1252-12A induced mitochondria-dependent apoptosis thus warranting further investigation.

\section{Materials and methods}

Cells and reagents. The leukemia cell lines HL-60, MOLM-13, U937, THP-1 and MV4-11 were donated by State Key Laboratory of Oncology in South China. Cells were cultured in RPMI-1640 (Gibco Life Technologies, Carlsbad, CA, USA) supplemented with $10 \%$ fetal bovine serum (FBS22A; Carpricorn Scientific Gmbh, Ebsdorfergrund, Germany) and incubated at $37^{\circ} \mathrm{C}$ with $5 \% \mathrm{CO}_{2}$. APG-1252-12A was kindly provided by the Ascentage Pharma Group Corp Inc. (Taizhou, China) and was dissolved in pure dimethyl sulfoxide (DMSO; Sigma-Aldrich, St. Louis, MO, USA) with a stock concentration of $40 \mathrm{mmol} / 1$, stored at $-20^{\circ} \mathrm{C}$, and diluted in the corresponding culture medium just before use.

Cell viability assay. Cell proliferation was determined by CellTiter 96AQueous MTS (3-[4,5-dimethylthiazol-2-yl]5-[3-carboxymethoxyphenyl]-2-[4-sulfophenyl]-2H-tetrazolium, inner salt) assay. AML cell lines were seeded 10,000-50,000
Table I. The $\mathrm{IC}_{50}$ values $(\mu \mathrm{M})$ of APG-1252-12A in five AML cell lines.

\begin{tabular}{lrcc}
\hline Cell lines & $24 \mathrm{~h}$ & $48 \mathrm{~h}$ & $72 \mathrm{~h}$ \\
\hline HL-60 & $5.35 \pm 1.04$ & $1.52 \pm 0.30$ & $1.40 \pm 0.43$ \\
MOLM-13 & $0.15 \pm 0.06$ & $0.14 \pm 0.03$ & $0.04 \pm 0.01$ \\
MV4-11 & $0.19 \pm 0.09$ & $0.02 \pm 0.02$ & $0.03 \pm 0.00$ \\
THP-1 & $1.09 \pm 0.45$ & $1.06 \pm 0.08$ & $0.12 \pm 0.01$ \\
U937 & $16.61 \pm 1.93$ & $2.22 \pm 0.34$ & $1.23 \pm 0.23$
\end{tabular}

Data are the mean \pm SEM of three independent experiments.

onto 96-well plates containing $200 \mu \mathrm{l}$ of culture medium per well and treated with APG-1252-12A of serial concentrations for 24, 48 and $72 \mathrm{~h}$, respectively. After that, $40 \mu \mathrm{l}$ of MTS (Promega, Madison, WI, USA) was added to each well and reacted for another $4 \mathrm{~h}$ at $37^{\circ} \mathrm{C}$. Then the absorbance value was measured with a spectrophotometer at $490 \mathrm{~nm}$. Cell viability was expressed as mean \pm SD of absorbance and analyzed with nonlinear regression on GraphPad Prism version 6.0. The values were performed in triplicate as a percentage relative to those obtained in untreated controls.

Apoptosis detection with nuclear staining. The morphological assessment of apoptotic HL-60 cells was detected by Hoechst 33258 (Beyotime Institute of Biotechnology, Jiangsu, China) staining. Cells $(20,000)$ were plated in each of 6-well plate and incubated with various concentrations of APG-1252-12A and 0.1\% DMSO for $24 \mathrm{~h}$. The staining was performed according to the manufacturer's protocol. The morphological features of apoptosis were observed by fluorescence microscope (Olympus, Tokyo, Japan).

Flow cytometry analysis of apoptosis and cell cycle. Cell apoptosis was determined with an Annexin V-propidium iodide (PI) apoptosis detection kit (KGA108; KeyGen Biotech, Nanjing, China) by flow cytometry (Beckman Coulter, Fullerton, CA, USA). Cells $(200,000)$ were seeded into each well of a 6-well plate and treated with indicated concentration of drug or DMSO for 24 or $48 \mathrm{~h}$. After treatment, cells were harvested and washed twice with phosphate buffered saline (PBS), and resuspended in $500 \mu \mathrm{l}$ binding buffer containing $5 \mu \mathrm{l}$ Annexin V FITC and $5 \mu \mathrm{l}$ propidium iodide (KeyGen Biotech). Experiments were analyzed after incubating out of light in the staining solution for $10 \mathrm{~min}$.

Flow cytometry was performed to analyze cell cycle position. After treatment, cells were collected, washed and fixed in $70 \%$ cold ethanol at $4^{\circ} \mathrm{C}$ overnight. Next, the cells were incubated with RNase for $30 \mathrm{~min}$ at $37^{\circ} \mathrm{C}$, then stained with PI (Cell cycle Detection kit, KeyGen) in the dark at $4^{\circ} \mathrm{C}$ for another $30 \mathrm{~min}$. Cells were analyzed with a FACS Calibur flow cytometer (Beckman Coulter), and the data were analyzed using ModFit LT 3.2 software.

Western blot analysis. Cells were lysed with 1X Cell Lysis Buffer (\#9803: Cell Signaling Technology, Danvers, MA, USA), and protein concentration was measured with the Pierce BCA 

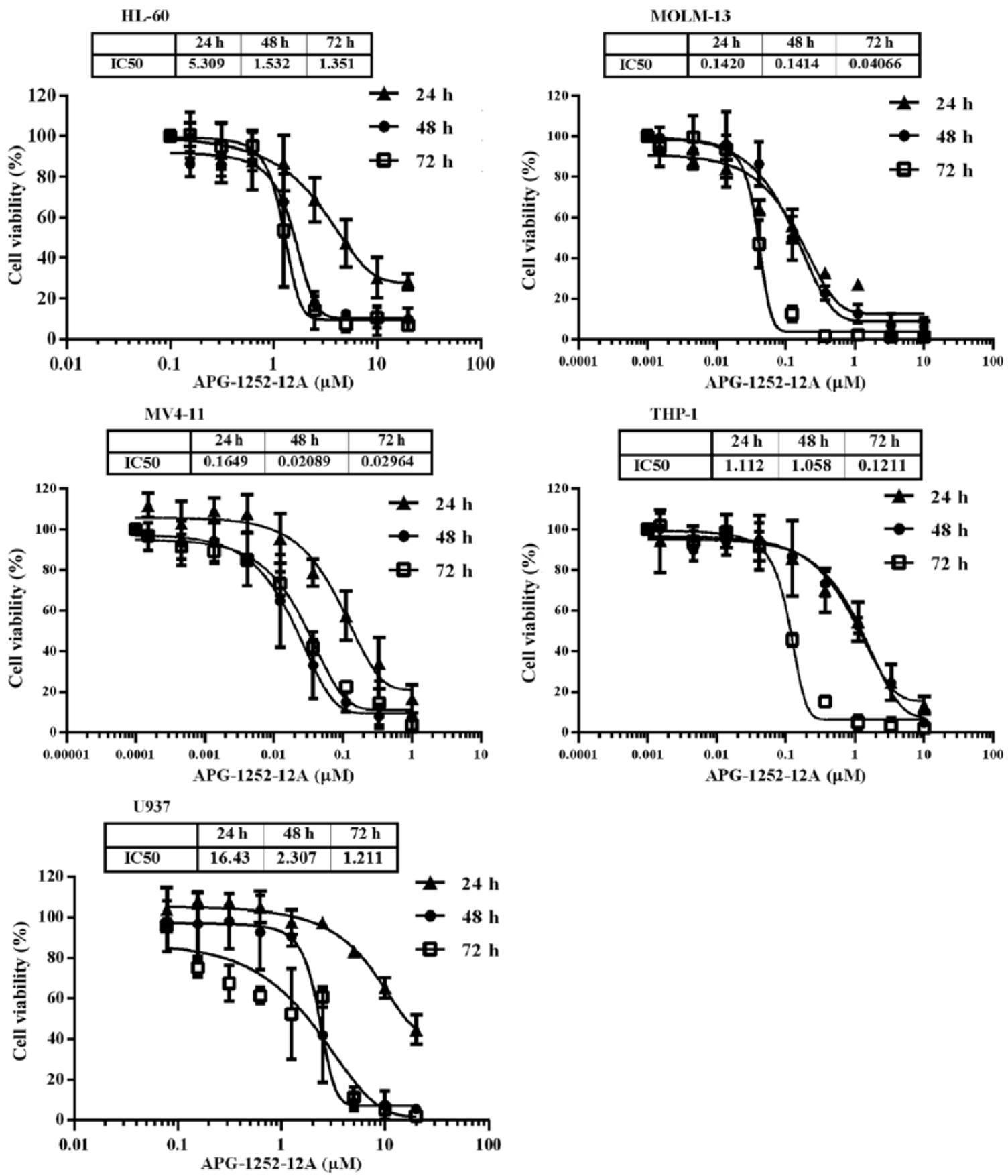

Figure 1. Anti-proliferative activity of APG-1252-12A in leukemia cell lines. MTS assays were performed using five cell lines: HL-60, MOLM-13, MV4-11, THP-1, and U937. The cells were treated with APG-1252-12A at various concentrations and 0.1\% DMSO served as control group for 24, 48 and $72 \mathrm{~h}$. The data are presented as the means of three independent experiments, with error bars indicating the standard deviation (SD).

protein assay kit. Total cell lysates were extracted and separated by electrophoresis in 8-15\% SDS-polyacrylamide gel and transferred to PVDF membranes (Roche, Basel, Switzerland). Following blockage in 5\% non-fat milk, PVDF membranes were incubated with anti-Mcl-1 (94296), Bcl-2 (4223), Bcl-xl (2764), anti-Bax (2772), anti-Bak (6947), anti-cleaved caspase-3 (9661), anti-caspase-3 (9665), anti-cytochrome c (4272), GAPDH (2118), anti- $\beta$-actin (4970, Cell Signaling Technology) or anti-PARP-1 (sc-7150), anti-Bim antibody (sc-374358; Santa Cruz Biotechnology Santa Cruz, CA, USA). The secondary anti-mouse (sc-2005) and anti-rabbit (sc-2004) antibodies were purchased from Santa Cruz Biotechnology. Antigen-antibody complexes were detected using Bio-Rad Clarity ${ }^{\mathrm{TM}}$ western ECL substrate and protein level were quantified by Image Lab (Bio-Rad Laboratory, Hercules, CA, USA).

Mitochondrial cytochrome c release assay. HL-60 cells were pretreated with $2.5 \mu \mathrm{mol} / 1$ of APG-1252-12A for $6 \mathrm{~h}$. Cytoplasmic fractionation was isolated using the Cytosol/ Mitochondria Fractionation kit (\#QIA88: Merck Millipore, Darmstadt, Germany). Following the kit recommendations, cytosolic fractions were isolated from HL-60 cells. The amount of cytochrome $\mathrm{c}$ in cytosol fraction was determined by western blot analysis as described above. 

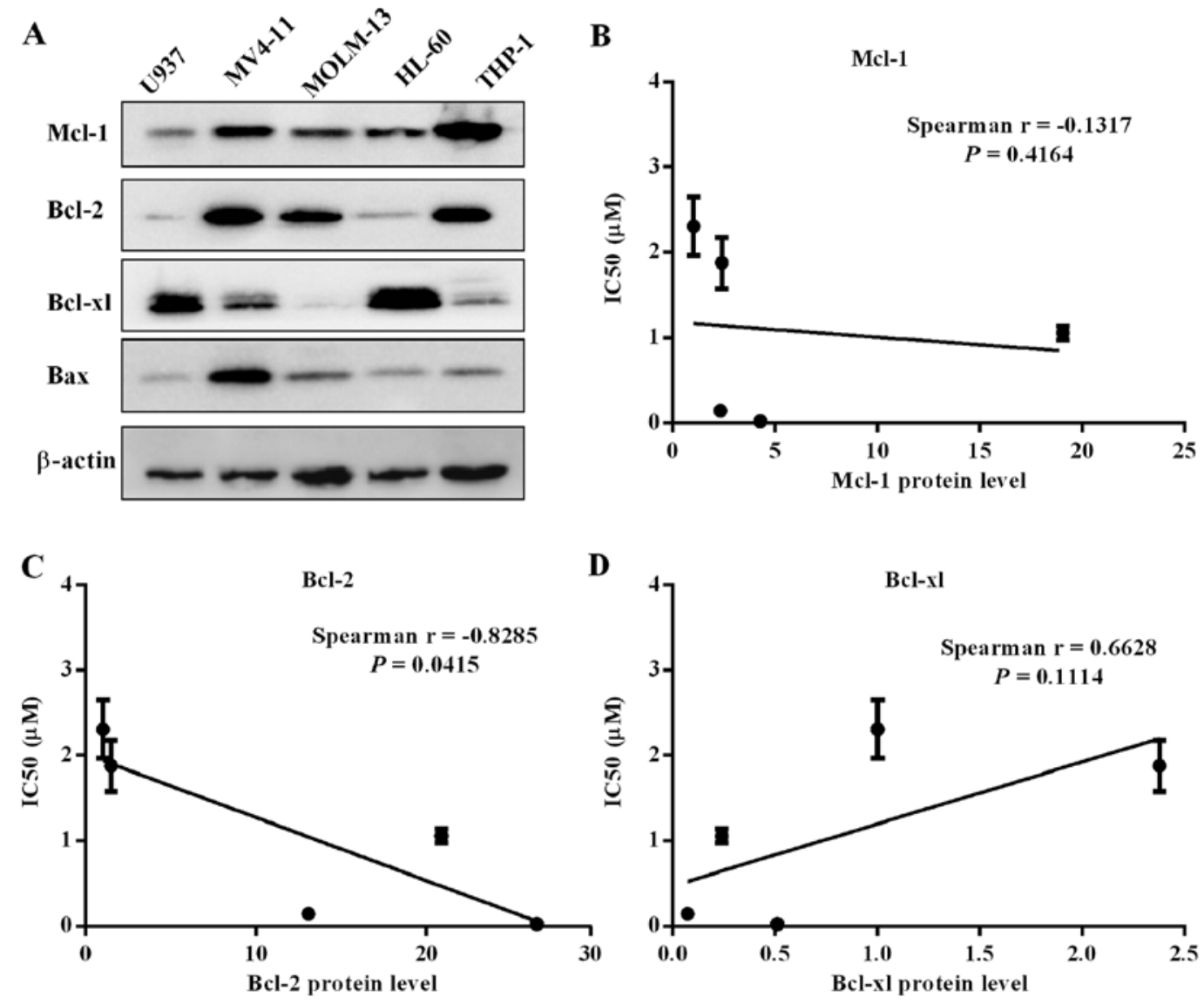

Figure 2. Endogenous Bcl-2 family protein level in five leukemia cell lines. (A) Western blot analysis of Bcl-2 family proteins in untreated leukemia cells. The band intensity was quantified with Image Lab software, and displayed numerically as a ratio of the band intensity detected in the U937 cells. (B-D) The nonparametric one-tailed Spearman's test was used to determine the correlation coefficient between $\mathrm{IC}_{50}$ values and protein expression. The P-values provided are nominal P-values not corrected for multiple comparisons. Significant correlations were observed between APG-1252-12A IC $_{50}$ values and Bcl-2 protein levels.

Statistical analysis. $\mathrm{IC}_{50}$ values were calculated by non-liner regression analysis with GraphPad Prism software v6.0 (GraphPad Software, La Jolla, CA, USA). The results were expressed as the mean \pm standard error of mean (SEM) from at least three independent experiments. One-way analysis of variance (ANOVA) was used to compare the means between groups by SPSS 20.0 software. Differences in P-value $<0.05$ were considered statistically significant.

\section{Results}

APG-1252-12A inhibits growth potently in five leukemia cell lines. To test the potential utility of APG-1252-12A in leukemia, we exposed five leukemia cell lines with increasing concentrations of APG-1252-12A for 24, 48 and $72 \mathrm{~h}$ and then determined the $\mathrm{IC}_{50}$ values. The viability of these cell lines after treatment decreased significantly in a time- and dosedependent manner (Fig. 1). The $\mathrm{IC}_{50}$ of APG-1252-12A ranged from $<100 \mathrm{nM}$ to $>1000 \mathrm{nM}$ and MV4-11 was the most sensitive cell line (Table I).

Bcl-2 family protein level in five leukemia cell lines. To further clarify the on-target action of cell killing via selectively binding with Bcl-1/Bcl-xl, we analyzed whether there were correlates of cell line sensitivity to APG-1252-12A. The expression of three $\mathrm{Bcl}-2$ family proteins were determined by western blot analysis (Fig. 2A). Spearman's analysis was performed to assess correlation between $\mathrm{IC}_{50}$ values and protein expression. The expression level of Bcl-2 correlated with sensitivity to the drug, while levels of Bcl-xl and Mcl-1 had no correlation with the drug sensitivity (Fig. 2B-D). The MV4-11 and MOLM-13 cells with high levels of Bcl-2 protein and relatively low Bcl-xl expression were more insensitive to APG-1252-12A. High expression of Bcl-xl in HL-60 and U937 cells might explain the killing mechanism of targeting Bcl-xl. THP-1 cell line had high level of Bcl-2 and Mcl-1 as well as relatively low level of Bcl-xl which supported that sensitivity to APG-1252-12A was correlated with Bcl-2 protein level.

APG-1252-12A induces apoptosis in HL-60 cells. Hoechst 33258 staining and flow cytometry were used to evaluate APG-1252-12A inducing apoptosis in HL-60 cells. Increased apoptosis was shown by analysis of nuclei changes with the electron microscopic analysis (Fig. 3A). The apoptotic bodies and nuclear fragments were stained light blue, and the normal cells were stained blue. The nuclei of the cells appeared normal, round and large with regular contours in the control groups. Cells with smaller nuclei and condensed chromatin were rare. By contrast, the treated cells showed strong morphological alterations such as nuclear shrinkage, intense fluorescence of nuclei and nuclear fragmentation. Apoptosis detection by Annexin V and PI staining showed 
A

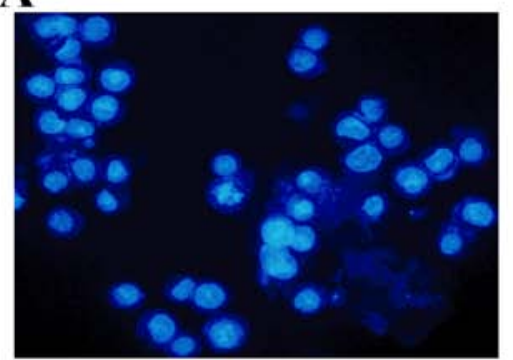

Control

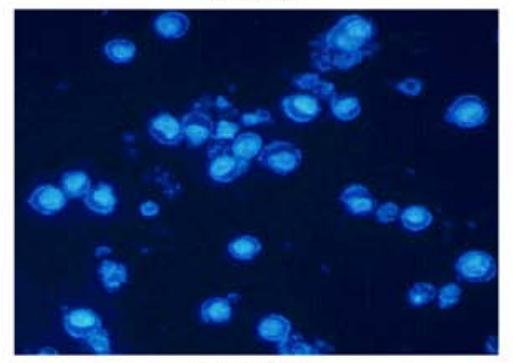

$2.5 \mu \mathrm{M}$

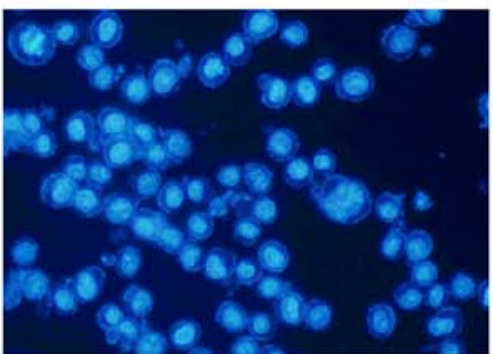

$0.625 \mu \mathrm{M}$

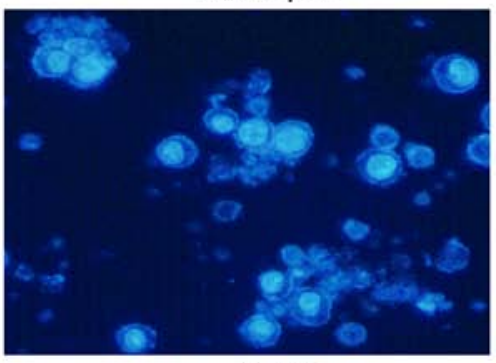

$5 \mu \mathbf{M}$

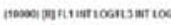

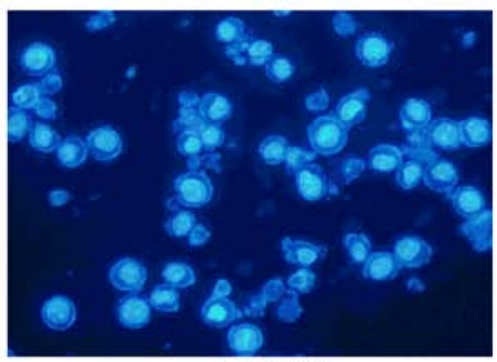

$1.25 \mu \mathrm{M}$

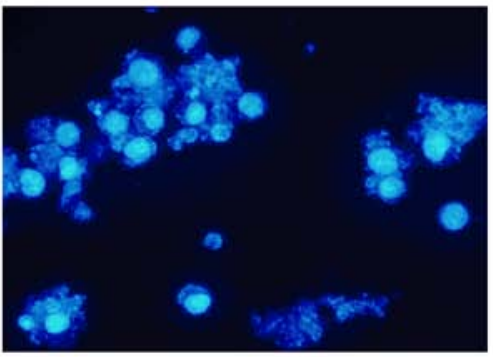

$10 \mu \mathrm{M}$

B
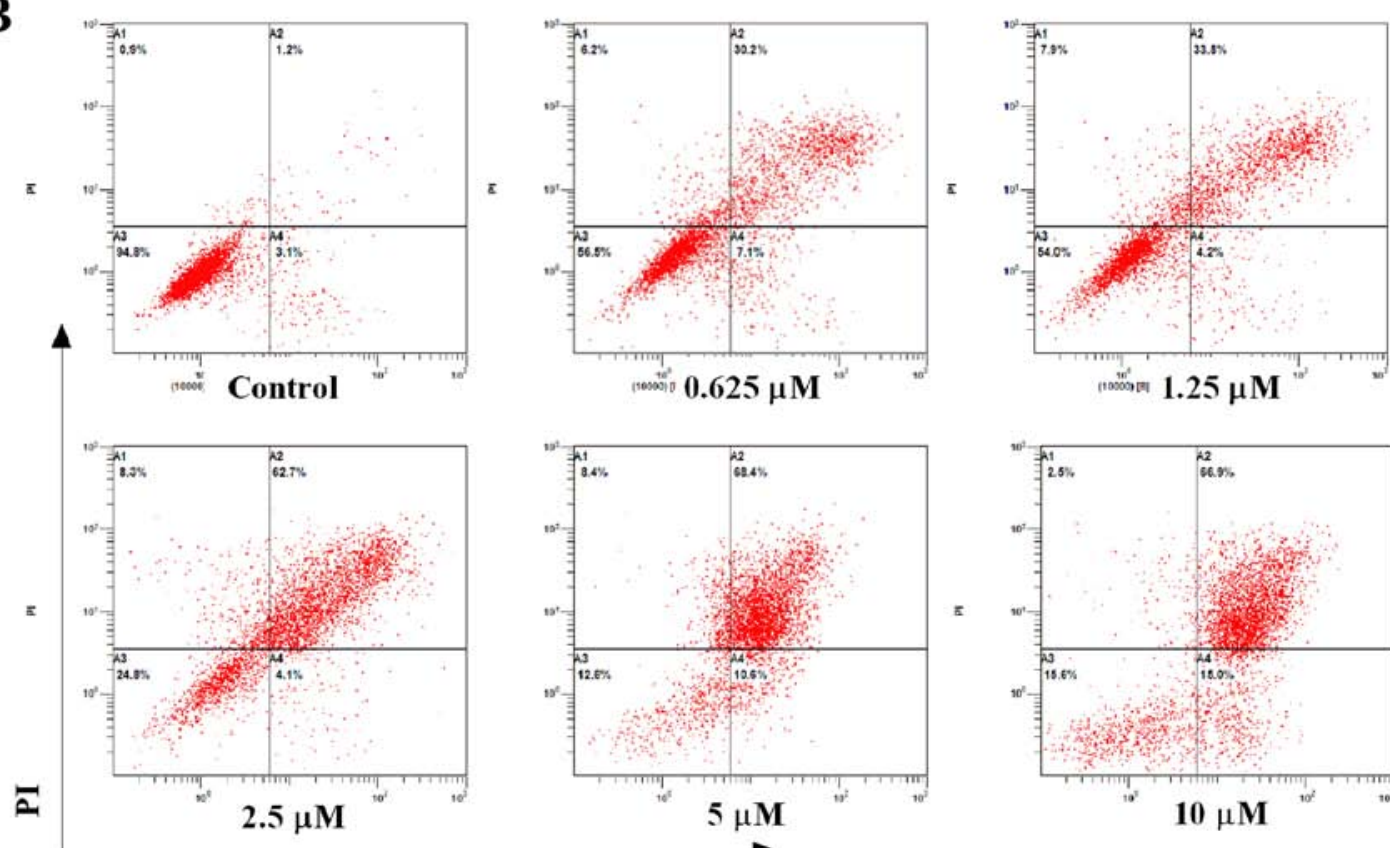

Annexin V
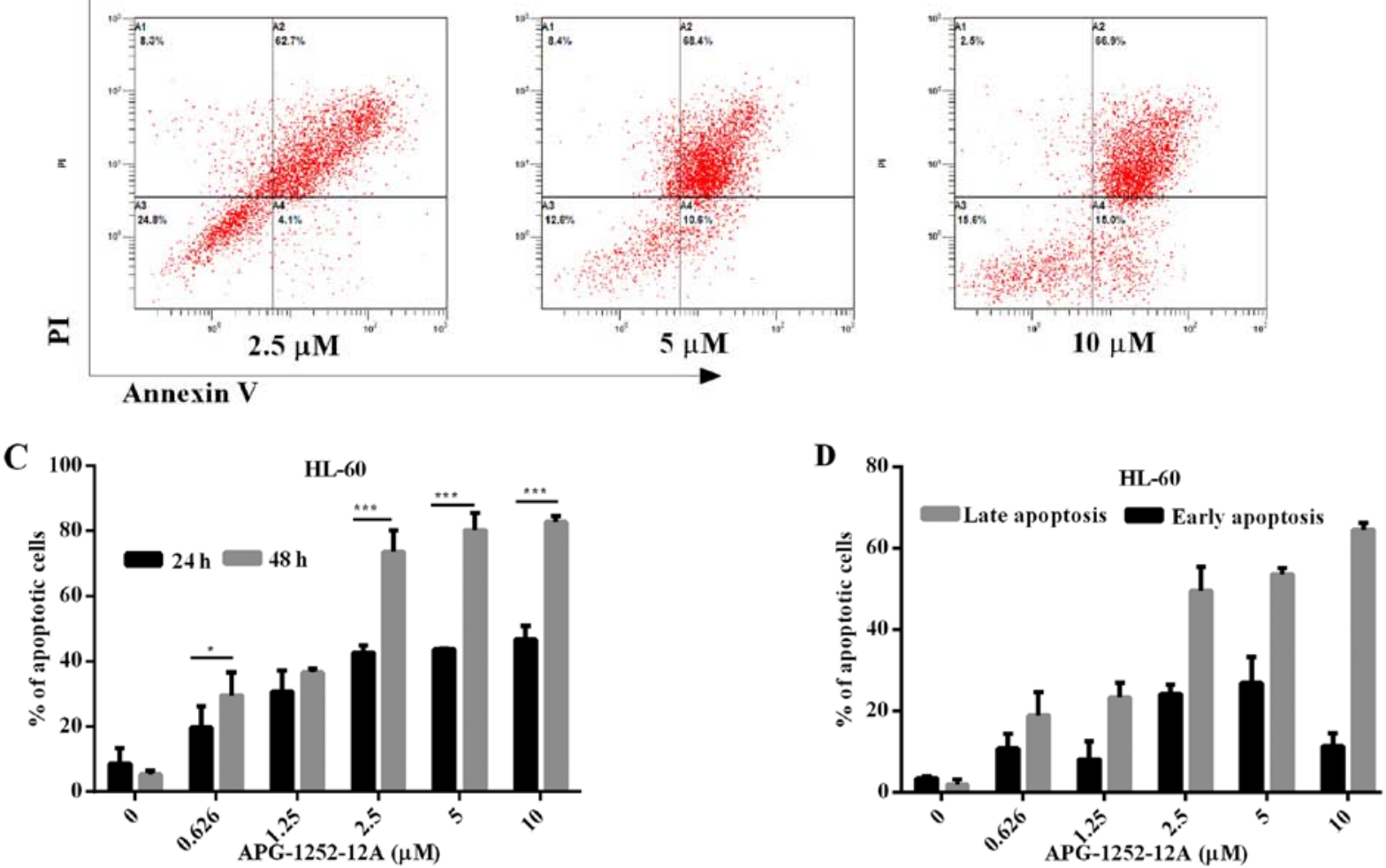

Figure 3. APG-1252-12A induces apoptosis in HL-60 cells. (A) HL-60 cells were stained with Hoechst 33258 and examined under fluorescent microscope after incubating APG-1252-12A for $24 \mathrm{~h}$. (B) Representative results showing HL-60 cells in apoptosis after treatment without or with APG-1252-12A for 48 h. Flow cytometric dot plots of Annexin V/FITC and PI staining. (C) Statistical analysis of the propotion of apoptotic cells. HL-60 cells were incubated with increasing concentrations of APG-1252-12A for 24 or $48 \mathrm{~h}$. (D) Distribution chart of early and late apoptotic HL-60 cells after $48 \mathrm{~h}$ treatment of APG-1252-12A. The data are presented as the means of three independent experiments, with error bars indicating the standard deviation (SD). $\left({ }^{*} \mathrm{P}<0.05,{ }^{* * *} \mathrm{P}<0.01,{ }^{* * * *} \mathrm{P}<0.001\right)$. 

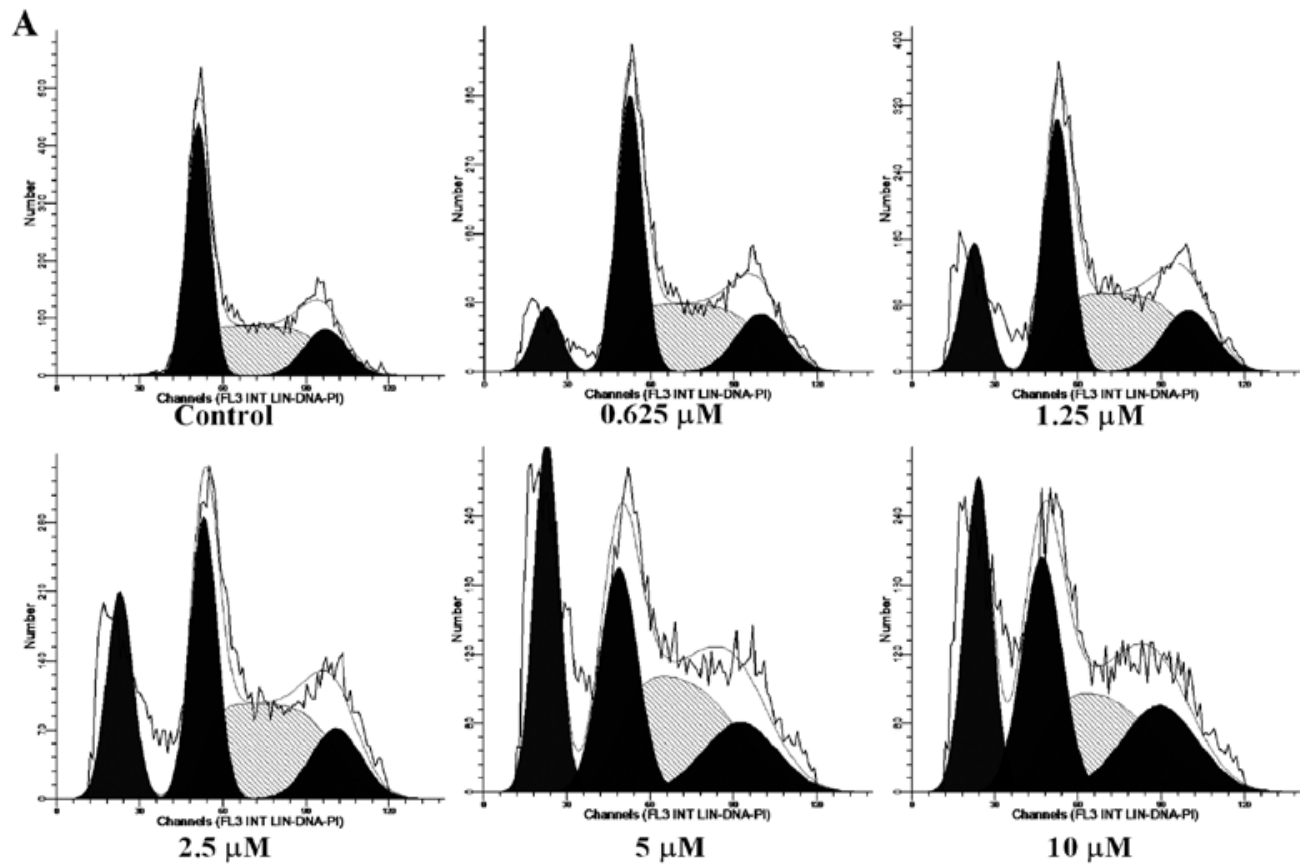

B

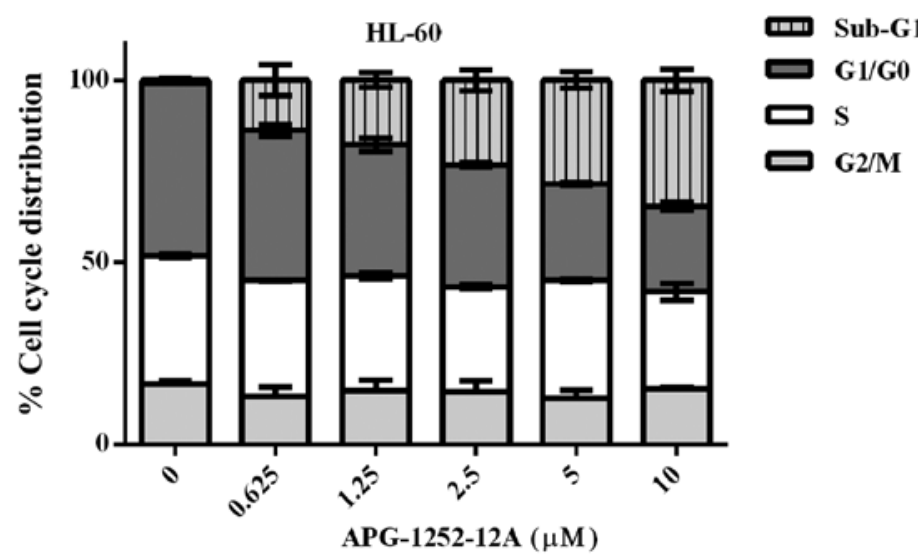

Figure 4. Cell cycle changes in HL-60 cells treated with the indicated concentrations of APG-1252-12A for 24 h. Histograms show the percentage of HL-60 cells in Sub-G1, G1, S, and G2/M phases in three independent experiments.

that when treated with APG-1252-12A alone, dramatic increase of Annexin $\mathrm{V}$ positive cells was seen in HL-60 cells (Fig. 3B). Flow cytometry also indicated that treatment with increasing concentrations of the drug resulted in a significant decrease of cell counts and induced apoptosis in a dose-dependent manner. Time course analysis of cells exposed to APG-1252-12A (10 $\mu \mathrm{mol} / 1)$ revealed approximately $47 \%$ cell death at $24 \mathrm{~h}$, and substantially more pronounced lethality after 48 h (83\%, Fig. 3C). An early and late apoptotic cell distribution chart shows more late stage HL-60 apoptotic cells than early stage after $48 \mathrm{~h}$ treatment of APG-1252-12A (Fig. 3D).

The sub-G1 phase increases after APG-1252-12A treatment. Cell cycle analysis of the propidium iodine stained DNA was performed in HL-60 cells. The percentage of cells in sub-G1 fraction increased significantly, pointing to APG-1252-12Ainduced cell death and DNA fragmentation (Fig. 4). Treatment with increasing concentrations of APG-1252-12A resulted in a significant increase in the percentage of cells in the sub-G1 phase. The remaining living cells showed no significant increase in the percentage of cells in the $S$ phase of the cell cycle and the percentage of cells in the G1 and G2/M phase showed similar results. No statistically significant correlation between APG-1252-12A sensitivity and cell cycle was found.

Effect of APG-1252-12A on Bcl-2 family protein expression in $H L-60$ cells. To further investigate the effect of APG-1252-12A on the protein expression level of Bcl-2 family members, we chose HL-60 for analysis. After treating with serial concentrations of APG-1252-12A for $24 \mathrm{~h}$, there were no significant alternations in the protein expression of Bcl-2 family except the suppression of Mcl-1 in HL-60 cells (Fig. 5A and D). A time course of Bcl-2, Bcl-xl, Bak and Bax protein levels showed that the APG-1252-12A treatment in HL-60 cells did not change their expression levels (Fig. 5B).

APG-1252-12A promotes cytochrome c release in $H L-60$ cells. We also observed that cell death was induced by APG-1252-12A 
A

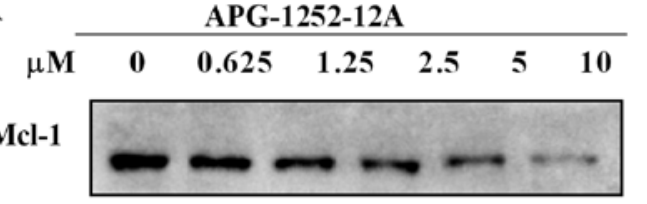

Bcl-2

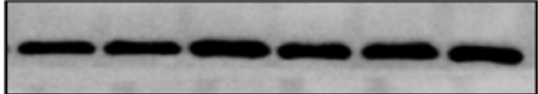

Bcl-xl

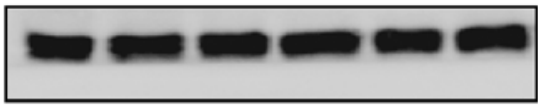

Bax
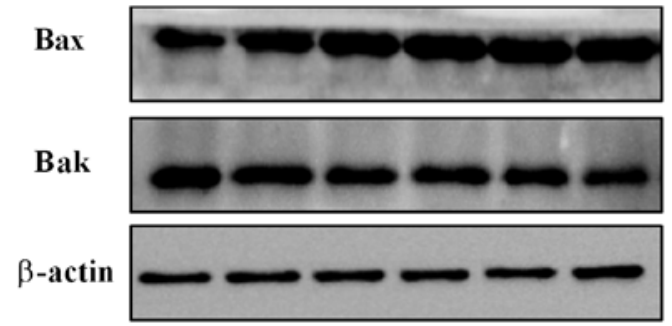

C

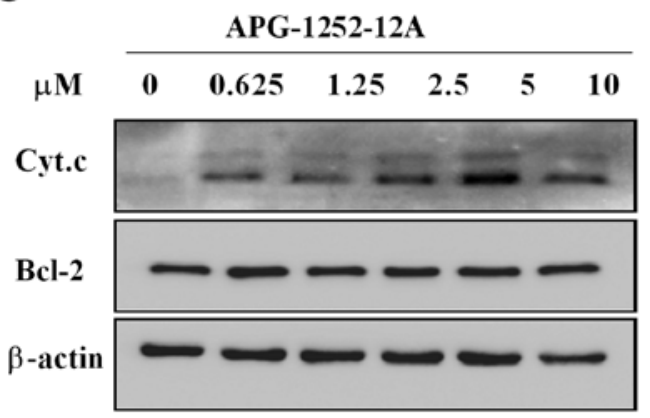

B

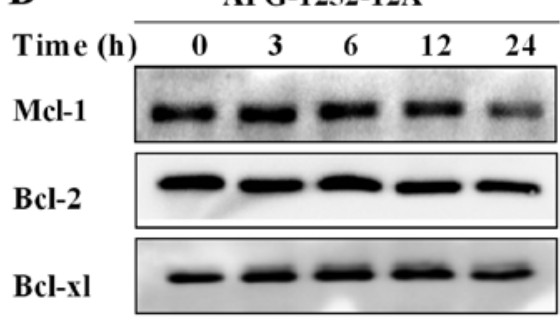

Bax

Bak

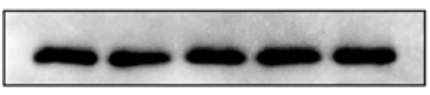

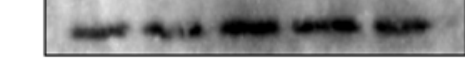

$\beta$-actin
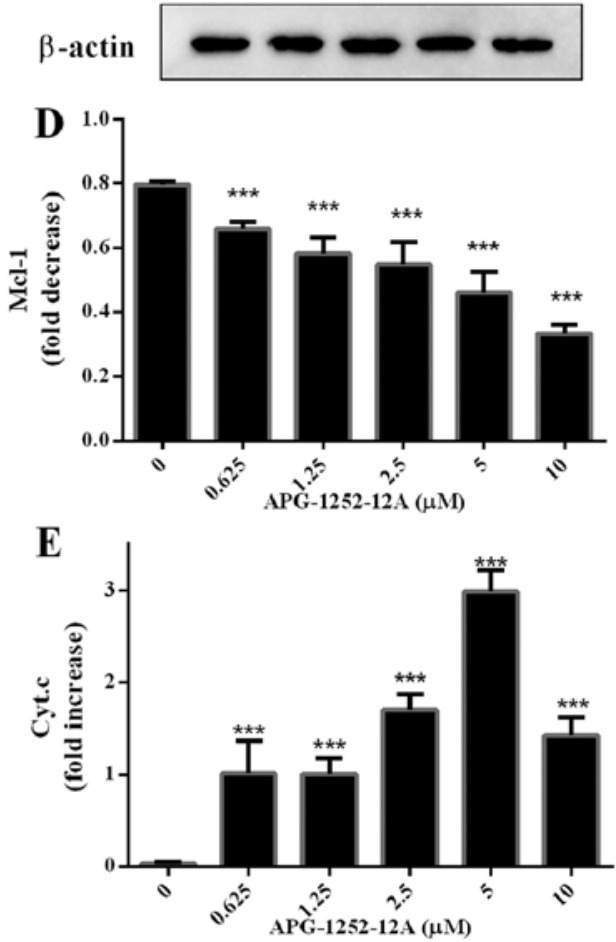

Figure 5. Effect of APG-1252-12A on HL-60 cells. (A) Bcl-2 family protein levels of Mcl-1, Bcl-2, Bcl-xl, Bax and Bak were examined by western blot analysis . HL-60 cells were treated with serial concentration of APG-1252-12A for $24 \mathrm{~h}$. (B) Cells were treated with APG-1252-12A (1.25 $\mu \mathrm{M})$ for the indicated time points and whole cell extracts were analyzed by immunoblotting. (C) HL-60 cells were treated APG-1252-12A for $6 \mathrm{~h}$ and cytosolic fraction was isolated for western blot analysis. (D) Mcl-1 expression in (A) was quantified by Image Lab and normalized to $\beta$-actin. (E) The relative expression of cytochrome $\mathrm{c}$ in (C) was normalized to $\beta$-actin. Error bars represent the standard deviation of three independent experiments. $\left({ }^{*} \mathrm{P}<0.05,{ }^{* * *} \mathrm{P}<0.01,{ }^{* * * *} \mathrm{P}<0.001 \mathrm{APG}-1252-12 \mathrm{~A}\right.$ treated group vs. control).

that underwent cytochrome c release (Fig. 5C and E). Cytoplasmic cytochrome $\mathrm{c}$ level was detected by western blot analysis. APG-1252-12A induced cytochrome $\mathrm{c}$ release at a concentration of $<0.625 \mu \mathrm{mol} / 1$.

APG-1252-12A induces caspase-3 activation in HL-60 cells. Western blot analysis was performed with antibodies against PARP-1, caspase-3, and cleaved caspase-3. APG-1252-12A led to increase of cleaved PARP, cleaved caspase- 3 and decrease of caspase- 3 in HL-60 cells in a concentration-dependent manner (Fig. 6A-D). The marked cleavage/activation of caspases-3 and PARP-1 in HL-60 pronounced the loss in mitochondrial membrane potential (MOMP). These findings indicated that inhibition of anti-apoptotic Bcl-2 and Bcl-xl caused MOMP, promoting cytochrome $\mathrm{c}$ release followed by caspase activation.

\section{Discussion}

As multiple studies have implicated the role of Bcl-2 family proteins in AML pathogenesis and prognosis (27-29), small molecule $\mathrm{BH} 3$-mimetics that inhibit the anti-apoptotic functions of Bcl-2 and Bcl-xL have been developed $(15,18)$. In clinical trials, ABT-263 significantly reduced tumour burden in most patients with CLL as a single agent or in combination with other conventional treatments $(30,31)$. Although thrombocytopenia limited the use of ABT-263 in patients, the observed efficacy underscored the therapeutic potential of selective Bcl-2 family inhibitors. ABT-199 was also investigated as a single agent or in combination with other anti-cancer therapies for CLL $(20,32)$. Achievement of the primary end point in the study led to the first successful US Food and Drug Aministration (FDA) registration for 
A

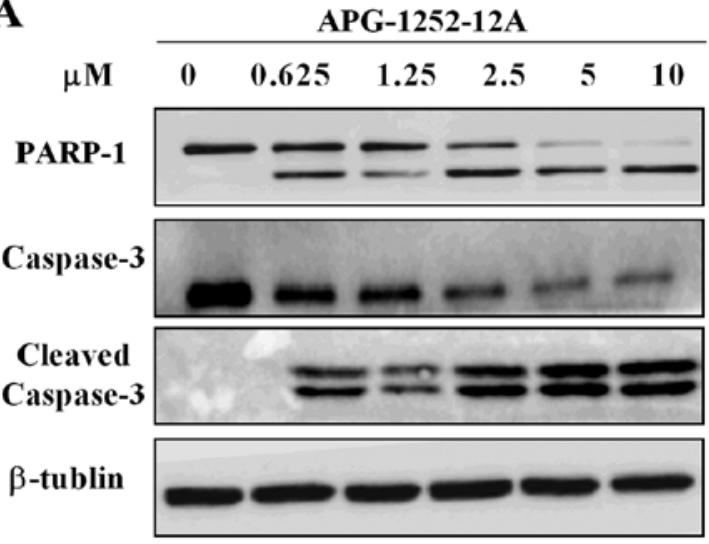

C

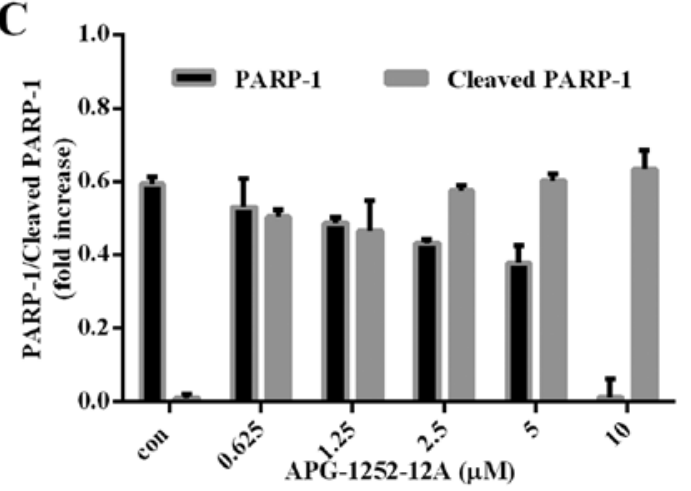

B
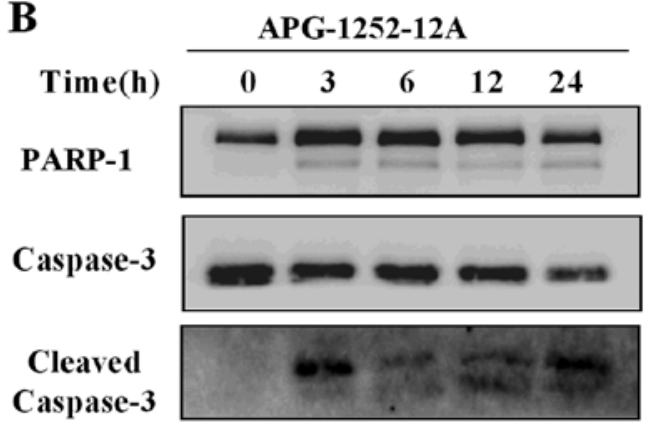

$\beta$-actin

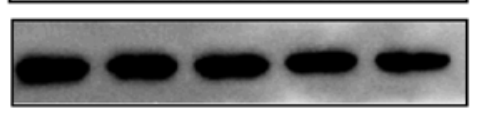

D

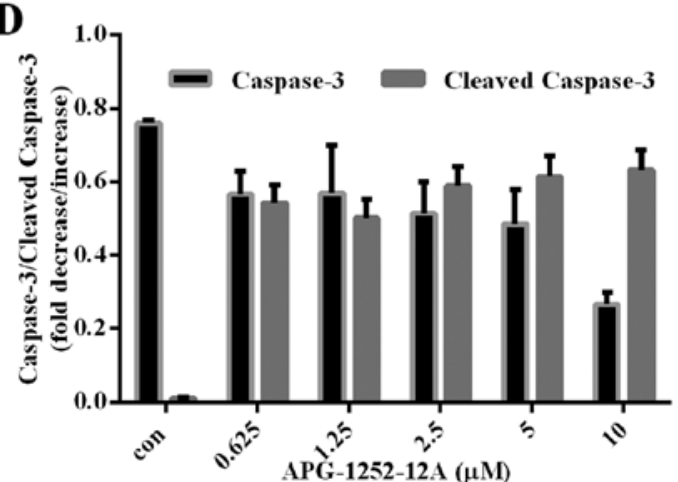

Figure 6. APG-1252-12A induces apoptosis associated with mitochondria-dependent pathway. (A) Western blot analysis of PARP-1, caspase-3 and cleaved caspase-3 in APG-1252-12A-treated HL-60 cells. (B) HL-60 cells were treated with APG-1252-12A (1.25 $\mu \mathrm{M})$ for 0, 3, 6, 12 and 24 h and were analyzed by immunoblotting. (C) Relative changes of PARP and cleaved PARP were examined in HL-60 cells. (D) The relative expression of caspase-3 and cleaved caspase-3 in APG-1252-12A-treated HL-60 cells were normalized to $\beta$-actin.

ABT-199. Bai and colleagues (25) identified APG-1252-12A as an active metabolic product of APG-1252 in vivo, and bound to Bcl-2 and Bcl-xl with sub-nanomalar affinities. In this study, we tested the impact of Bcl-2/Bcl-xl dual inhibitor APG-1252-12A in five leukemia cell lines. The results of MTS assay showed that application of APG-1252-12A to leukemia cell lines significantly inhibited cell proliferation. The $\mathrm{IC}_{50}$ was in low nanomolar range, a range might be achievable in clinical trials. In light of this observation, it is possible that the level of Bcl-2 family members might be related to sensitivity to APG-1252-12A.

We investigated whether the Bcl-2 protein level in five leukemia cell lines was associated with the sensitivity to APG-1252-12A. Leukemia cell lines express Bcl-2 with varied expression of Bcl-xl. Though ABT-737 bound to Bcl-2 and Bcl-xl proteins with similar affinities (14), it was surprising that the level of $\mathrm{Bcl}-\mathrm{xl}$ expression did not correlate with the sensitivity of AML cells to APG-1252-12A. The levels of Bcl-xl and Mcl-1 had no correlation with the drug sensitivity. It was found that increased expression of $\mathrm{Bcl}-2$ was associated with increased sensitivity to Bcl-2 inhibitor which was similar to those previously reported (10). The Bcl-2 protein level correlated with cell line sensitivity to APG-1252-12A suggested an on-target action of killing. The role of Bcl-2 in the survival of tumor cells is well established, so the drugs that inhibited these proteins might be useful therapeutically.

Herein, we demonstrated that HL-60 cells treated with APG-1252-12A developed an accumulation of apoptotic cells. The drug acted in a concentration- and time-dependent manner. Hoechst staining and flow cytometry analysis of APG-1252-12A-treated HL-60 cells suggested the occurrence of apoptosis. Furthermore, the effect of varying concentrations of inhibitors on cell cycle distribution was determined by flow cytometric analysis. The increase of the sub-G0/G1 phase of cells indicated typical late stages of apoptosis.

Studies in cell lines and primary cells have revealed that high expression of all anti-apoptotic Bcl-2 family members, Bcl-2, Bcl-xl, Bcl-w, A1 and Mcl-1, were capable of inhibiting the mitochondrial apoptotic pathway (33). We also investigated the mechanism of antitumor activity of APG-1252-12A. Our findings are consistent with the above studies that administration of APG-1252-12A to HL-60 cells rapidly induced hallmarks of apoptosis, including cytochrome c release, caspase-3 and PARP-1 activation. Normally, releasing cytochrome $\mathrm{c}$ from mitochondria to the cytoplasm is a critical signal of caspase activation (34-36). The occurrence of cytochrome c release suggested that APG-1252-12A might induce in AML a form of apoptotic cell death that can include caspase activation as an essential pathway. As MOMP and cytochrome c release are usually viewed as characteristics of no return in apoptosis, APG-1252-12A achieves a potent cell killing effect in AML cell line. The Bcl-2 anti-apoptotic members are helical proteins with an open groove that binds to the $\mathrm{BH} 3$ domain on the proapoptotic partner. The anti-apoptotic Bcl-2-like proteins provide a barrier against MOMP by binding proapoptotic $\mathrm{BH} 3$-only protein (such as Bim and Bid) and keeping multidomain target (Bax 
and Bak) in an inhibited state $(37,38)$. BH3 mimetic compounds, such as ABT-737 and ABT-263, binds to anti-apoptotic Bcl-2 family proteins and liberates proapoptotic $\mathrm{BH} 3$-only proteins. The proapoptotic $\mathrm{BH} 3$-only protein stimulate apoptosis not only by binding anti-apoptotic Bcl-2-like proteins to release Bax and Bak but also by directly activating Bax and Bak. Previous discoveries revealed that Bax and Bak have important roles in unleashing the effector phase of mitochondrial apoptosis and must change shape to cause MOMP and apoptosis (39-41).

The ability of APG-1252-12A to induce HL-60 mitochondrial apoptosis was confirmed in vitro. These findings have some implications for the investigation of APG-1252-12A, suggesting that inhibiting Bcl-2 and Bcl-xl protein could activate the intrinsic apoptotic pathway. Our work might provide a foundation for studies in APG-1252-12A as a single agent in vivo which can be exploited as a potential therapeutic drug in AML.

\section{Acknowledgements}

This study was supported by the National Natural Science Foundation of China (NSFC: 81101671) and Natural Science Foundation of Guangdong Province (2016A030313280).

\section{References}

1. National Cancer Institute: SEER Stat Fact Sheets: Acute Myeloid Leukemia (AML) NIH. http://seer.cancer.gov/statfacts/html/ amyl.html. Accessed May 19, 2016.

2. Irish JM, Anensen N, Hovland R, Skavland J, Borresen-Dale A-L, Bruserud O, Nolan GP and Gjertsen BT: Flt3 Y591 duplication and $\mathrm{Bcl}-2$ overexpression are detected in acute myeloid leukemia cells with high levels of phosphorylated wild-type p53. Blood 109: 2589-2596, 2007.

3. Hanahan D and Weinberg RA: Hallmarks of cancer: The next generation. Cell 144: 646-674, 2011.

4. Delbridge AR, Grabow S, Strasser A and Vaux DL: Thirty years of BCL-2: Translating cell death discoveries into novel cancer therapies. Nat Rev Cancer 16: 99-109, 2016.

5. Tsujimoto Y, Cossman J, Jaffe E and Croce CM: Involvement of the bcl-2 gene in human follicular lymphoma. Science 228: 1440-1443, 1985.

6. Cleary ML, Smith SD and Sklar J: Cloning and structural analysis of cDNAs for bcl-2 and a hybrid bcl-2/immunoglobulin transcript resulting from the $\mathrm{t}(14 ; 18)$ translocation. Cell 47 : 19-28, 1986.

7. Vaux DL, Cory S and Adams JM: Bcl-2 gene promotes haemopoietic cell survival and cooperates with c-myc to immortalize pre-B cells. Nature 335: 440-442, 1988.

8. Huang JZ, Sanger WG, Greiner TC, Staudt LM, Weisenburger DD, Pickering DL, Lynch JC, Armitage JO, Warnke RA, Alizadeh AA, et al: The $\mathrm{t}(14 ; 18)$ defines a unique subset of diffuse large $\mathrm{B}$-cell lymphoma with a germinal center B-cell gene expression profile. Blood 99: 2285-2290, 2002.

9. Minn AJ, Rudin CM, Boise LH and Thompson CB: Expression of bcl-xL can confer a multidrug resistance phenotype. Blood 86 1903-1910, 1995.

10. Pan R, Hogdal LJ, Benito JM, Bucci D, Han L, Borthakur G, Cortes J, DeAngelo DJ, Debose L, Mu H, et al: Selective BCL-2 inhibition by ABT-199 causes on-target cell death in acute myeloid leukemia. Cancer Discov 4: 362-375, 2014.

11. Ni Chonghaile T and Letai A: Mimicking the BH3 domain to kill cancer cells. Oncogene 27 (Suppl 1): S149-S157, 2008.

12. Merino D, Khaw SL, Glaser SP, Anderson DJ, Belmont LD, Wong C, Yue P, Robati M, Phipson B, Fairlie WD, et al: Bcl-2, $\mathrm{Bcl}-\mathrm{x}(\mathrm{L})$, and $\mathrm{Bcl}-\mathrm{w}$ are not equivalent targets of ABT-737 and navitoclax (ABT-263) in lymphoid and leukemic cells. Blood 119: 5807-5816, 2012.

13. Del Gaizo Moore V, Schlis KD, Sallan SE, Armstrong SA and Letai A: BCL-2 dependence and ABT-737 sensitivity in acute lymphoblastic leukemia. Blood 111: 2300-2309, 2008
14. Oltersdorf T, Elmore SW, Shoemaker AR, Armstrong RC, Augeri DJ, Belli BA, Bruncko M, Deckwerth TL, Dinges J, Hajduk PJ, et al: An inhibitor of Bcl-2 family proteins induces regression of solid tumours. Nature 435: 677-681, 2005.

15. Tse C, Shoemaker AR, Adickes J, Anderson MG, Chen J, Jin S, Johnson EF, Marsh KC, Mitten MJ, Nimmer P, et al: ABT-263: A potent and orally bioavailable Bcl-2 family inhibitor. Cancer Res 68: 3421-3428, 2008.

16. Gavathiotis E, Suzuki M, Davis ML, Pitter K, Bird GH, Katz SG, Tu H-C, Kim H, Cheng EH-Y, Tjandra N, et al: BAX activation is initiated at a novel interaction site. Nature 455: 1076-1081, 2008.

17. Konopleva M, Contractor R, Tsao T, Samudio I, Ruvolo PP, Kitada S, Deng X, Zhai D, Shi Y-X, Sneed T, et al: Mechanisms of apoptosis sensitivity and resistance to the $\mathrm{BH} 3$ mimetic ABT-737 in acute myeloid leukemia. Cancer Cell 10: 375-388, 2006.

18. Souers AJ, Leverson JD, Boghaert ER, Ackler SL, Catron ND, Chen J, Dayton BD, Ding H, Enschede SH, Fairbrother WJ, et al: ABT-199, a potent and selective BCL-2 inhibitor, achieves antitumor activity while sparing platelets. Nat Med 19: 202-208, 2013.

19. Vandenberg CJ and Cory S: ABT-199, a new Bcl-2-specific BH3 mimetic, has in vivo efficacy against aggressive Myc-driven mouse lymphomas without provoking thrombocytopenia. Blood 121: 2285-2288, 2013.

20. Roberts AW, Davids MS, Pagel JM, Kahl BS, Puvvada SD, Gerecitano JF, Kipps TJ, Anderson MA, Brown JR, Gressick L, et al: Targeting BCL2 with venetoclax in relapsed chronic lymphocytic leukemia. N Engl J Med 374: 311-322, 2016.

21. San-Miguel JF: Consolidation therapy in myeloma: A consolidated approach? Blood 120: 2-3, 2012.

22. Roberts AW, Advani RH, Kahl BS, Persky D, Sweetenham JW, Carney DA, Yang J, Busman TB, Enschede SH,Humerickhouse RA, et al: Phase 1 study of the safety, pharmacokinetics, and antitumour activity of the BCL2 inhibitor navitoclax in combination with rituximab in patients with relapsed or refractory CD20 lymphoid malignancies. Br J Haematol 170: 669-678, 2015.

23. Li T, Yuan G, Zhang L, Ye L, Li S, Fan Y and Sun J: ApoG2 inhibits the antiapoptotic protein, Mcl1, and induces mitochondriadependent apoptosis in human colorectal cancer cells. Mol Med Rep 12: 6976-6984, 2015.

24. Ye L, Yuan G, Xu F, Sun Y, Chen Z, Chen M, Li T, Sun P, Li S and Sun J: The small-molecule compound BM-1197 inhibits the antiapoptotic regulators $\mathrm{Bcl}-2 / \mathrm{Bcl}-\mathrm{xL}$ and triggers apoptotic cell death in human colorectal cancer cells. Tumour Biol 36: 3447-3455, 2015.

25. Bai L, Chen J, Liu L, McEachern D, Aguilar A, Zhou H, Yang CY, Wang H, Wen J, Wang G, et al: BM-1252 (APG-1252): A potent dual specific $\mathrm{Bcl}-2 / \mathrm{Bcl}-\mathrm{xL}$ inhibitor that achieves complete tumor regression with minimal platelet toxicity. Eur J Cancer 50: 109-110, 2014.

26. Wang H, Wang G, Du Z, Wu M, McEachern D, Aguilar A, Lin Y, Lin X, Wen J, Gu L, et al: Preclinical studies of a dual Bcl-2/ Bcl-xL inhibitor APG-1252 with strong anti-tumor efficacy and significantly reduced platelet toxicity. Eur J Cancer 50: 176-177, 2014.

27. Glaser SP, Lee EF, Trounson E, Bouillet P, Wei A, Fairlie WD, Izon DJ, Zuber J, Rappaport AR, Herold MJ, et al: Anti-apoptotic Mcl-1 is essential for the development and sustained growth of acute myeloid leukemia. Genes Dev 26: 120-125, 2012.

28. Högstrand K, Hejll E, Sander B, Rozell B, Larsson LG and Grandien A: Inhibition of the intrinsic but not the extrinsic apoptosis pathway accelerates and drives MYC-driven tumorigenesis towards acute myeloid leukemia. PLoS One 7: e31366, 2012.

29. Del Poeta G, Venditti A, Del Principe MI, Maurillo L, Buccisano F, Tamburini A, Cox MC, Franchi A, Bruno A, Mazzone C, et al: Amount of spontaneous apoptosis detected by $\mathrm{Bax} / \mathrm{Bcl}-2$ ratio predicts outcome in acute myeloid leukemia (AML). Blood 101: 2125-2131, 2003.

30. Roberts AW, Seymour JF, Brown JR, Wierda WG, Kipps TJ, Khaw SL, Carney DA, He SZ, Huang DCS, Xiong H, et al: Substantial susceptibility of chronic lymphocytic leukemia to BCL2 inhibition: Results of a phase I study of navitoclax in patients with relapsed or refractory disease. J Clin Oncol 30: 488-496, 2012.

31. Ackler S, Mitten MJ, Foster K, Oleksijew A, Refici M, Tahir SK, Xiao Y, Tse C, Frost DJ, Fesik SW, et al: The Bcl-2 inhibitor ABT-263 enhances the response of multiple chemotherapeutic regimens in hematologic tumors in vivo. Cancer Chemother Pharmacol 66: 869-880, 2010. 
32. Stilgenbauer S, Eichhorst B, Schetelig J, Coutre S, Seymour JF, Munir T, Puvvada SD, Wendtner C-M, Roberts AW, Jurczak W, et al: Venetoclax in relapsed or refractory chronic lymphocytic leukaemia with $17 \mathrm{p}$ deletion: A multicentre, open-label, phase 2 study. Lancet Oncol 17: 768-778, 2016.

33. Czabotar PE, Lessene G, Strasser A and Adams JM: Control of apoptosis by the BCL-2 protein family: Implications for physiology and therapy. Nat Rev Mol Cell Biol 15: 49-63, 2014.

34. Liu X, Kim CN, Yang J, Jemmerson R and Wang X: Induction of apoptotic program in cell-free extracts: Requirement for dATP and cytochrome c. Cell 86: 147-157, 1996.

35. Yang J, Liu X, Bhalla K, Kim CN, Ibrado AM, Cai J, Peng TI, Jones DP and Wang X: Prevention of apoptosis by Bcl-2: Release of cytochrome c from mitochondria blocked. Science 275: 1129-1132, 1997.

36. Kluck RM, Bossy-Wetzel E, Green DR and Newmeyer DD: The release of cytochrome $\mathrm{c}$ from mitochondria: A primary site for Bcl-2 regulation of apoptosis. Science 275: 1132-1136, 1997.

37. Adams JM and Cory S: The Bcl-2 apoptotic switch in cancer development and therapy. Oncogene 26: 1324-1337, 2007.
38. Willis SN and Adams JM: Life in the balance: How BH3-only proteins induce apoptosis. Curr Opin Cell Biol 17: 617-625, 2005.

39. Wei MC, Zong WX, Cheng EH, Lindsten T, Panoutsakopoulou V, Ross AJ, Roth KA, MacGregor GR, Thompson CB and Korsmeyer SJ: Proapoptotic BAX and BAK: A requisite gateway to mitochondrial dysfunction and death. Science 292: 727-730, 2001.

40. Czabotar PE, Westphal D, Dewson G, Ma S, Hockings C Fairlie WD, Lee EF, Yao S, Robin AY, Smith BJ, et al: Bax crystal structures reveal how $\mathrm{BH} 3$ domains activate Bax and nucleate its oligomerization to induce apoptosis. Cell 152: 519-531, 2013.

41. Dewson G and Kluck RM: Mechanisms by which Bak and Bax permeabilise mitochondria during apoptosis. J Cell Sci 122: 2801-2808, 2009. 